Ionescu C., Gheorghiu Diana, Iacob Gabriela, Haradja H.

The link between nuchal translucency and congenital heart disease

UMF Carol Davila, Bucharest

Clinical Emergency Hospital Sf Pantelimon, Bucharest, Romania

\begin{abstract}
The nuchal translucency is defined as a transient subcutaneous collection of fluid behind the fetal neck seen on ultrasonography at 11-14 weeks of gestation. In this current overview it was observed the relationship between increased nuchal translucency (NT) and fetal heart structure and function in chromosomally normal fetuses. Fetuses with an increases NT have an increased risk for congenital heart disease (CHD) and the combination between an increases NT, tricuspid regurgitation (TR) and an abnormal ductus venosus (DV) Doppler flow profile is a strong marker for CHD.
\end{abstract}

Keywords: nuchal translucency, congenital heart disease,

\section{Ionescu Crîngu}

E-mail : antoniuginec@yahoo.com

\section{Introduction}

The nuchal translucency is defined as a transient subcutaneous collection of fluid behind the fetal neck seen on ultrasonography at 11-14 weeks of gestation [1]. The 95th percentile for NT measurement increases with gestational age between week 11-14 of gestation and is around $2.5 \mathrm{~mm}$ depending on crown rump length, whereas the 99th percentile is 3.5 $\mathrm{mm}$, and decreases after week 14 of gestation along with the reduction of the placental resistance and the beginning of the renal function $[2,3]$.

Fetal cardiology it is a specialty that continues to evolve rapidly for pediatric cardiologists and fetal medicine specialists. In this current overview it was observed the relationship between increased nuchal translucency (NT) and fetal heart structure and function in chromosomally normal fetuses. Fetuses with an increases NT have an increased risk for congenital heart disease (CHD), and this risk increases with increasing NT measurement. The combination between an increases NT, tricuspid regurgitation (TR) and an abnormal ductus venosus (DV) Doppler flow profile is a strong marker for CHD and should be followed by a fetal echocardiogram at 20 weeks of gestation in fetuses with an NT $>95$ th percentile, and also if it is found an increased NT associated with a tricuspid regurgitation or an abnormal DV flow 
pattern, or when the NT measurement is over 99th percentile, it is indicated an earlier echocardiogram and a repeat scan around 20 weeks of gestation.

An increased NT is not only a marker for chromosomal anomalies but also a nonspecific one for disturbance in normal early development. CHD are the most common structural and genetic disorders observed in normal karyotype fetuses with an enlarged NT $[4,5,6]$.

\section{The risk of congenital heart disease and nuchal translucency}

Hyett et al. [7] reported that in a cohort of 29154 pregnancies, $56 \%$ of the fetuses with major CHD had an increased NT measurement. It was observed an increased prevalence of CHD associated with increased NT thickness. The NT measurement could be the first screening step in the detection of CHD. NT screening is only a modest efficient strategy for detecting all CHD when is used alone, but may be effective in detecting specific CHD likely to benefit from prenatal diagnosis.

In a meta-analysis including 58492 fetuses, Makrydimas et al. [8] found that a NT measurement $>$ 99th percentile had a sensitivity of $31 \%$ and specificity of $98.7 \%$, with a positive likelihood ratio of 24 for the diagnosis of major CHD. A sensitivity of $37 \%$ and specificity of $96.6 \%$ was found using the 95th percentile cut-off. Simpson et al. [9] found a sensitivity of only $15.4 \%$ using 2.0 multiples of the median (MoM) in a prospective study of 34622 fetuses, but their low detection may be explained by the exclusion of the septated cystic hygroma. If they had included the septated cystic hygroma, their detection of the CHD would have been 35,3\% [10].

The median NT thickness is significantly higher in fetuses with major CHD compared to those with normal hearts [11]. The median age for CHD diagnosis was 16.1 weeks of gestation when NT was $>3.5 \mathrm{~mm}$ compared to 22.1 weeks of gestation when was $<3.5 \mathrm{~mm}$ [12]. The frequency of CHD varies from $0.6-5 \%$ when the NT is between $2.5-3.5 \mathrm{~mm}$, to $64 \%$ when the NT measurement is above $8.5 \mathrm{~mm}$ $[13,14,15]$.

\section{Abnormal ductus venosus Doppler flow profile and congenital heart disease}

In literature is encouraged the idea that the fluid accumulation causing the nuchal edema is caused by cardiac failure, due to intrinsic myocardial dysfunction or secondary to the CHD [16]. An increased mRNA of cardiac atrial and brain natriuretic peptide in trisomic fetuses with an increased NT seems to support this hypothesis [17]. In monochorionic twins, an early marker of twinto-twin transfusion syndrome is the discordancy for increased NT [18]. The early imbalance in the circulatory volume, shared by the twins could cause the nuchal edema. Also, an important aspect is that if cardiac failure causes the nuchal edema, then it could also be expected cardiomegaly, ascites, peripheral edema and pericardial and pleural effusions, but they are not seen in fetuses with an increased NT.

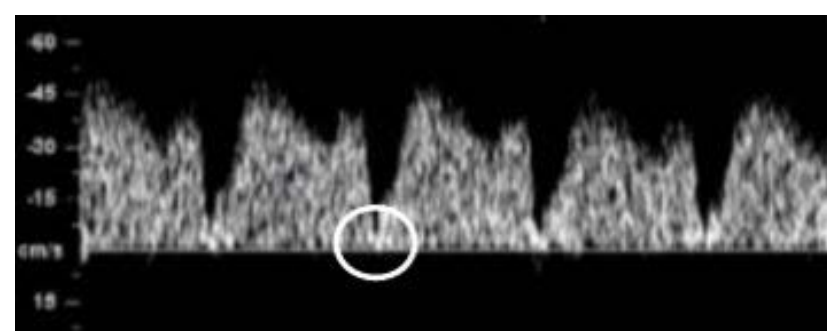

A

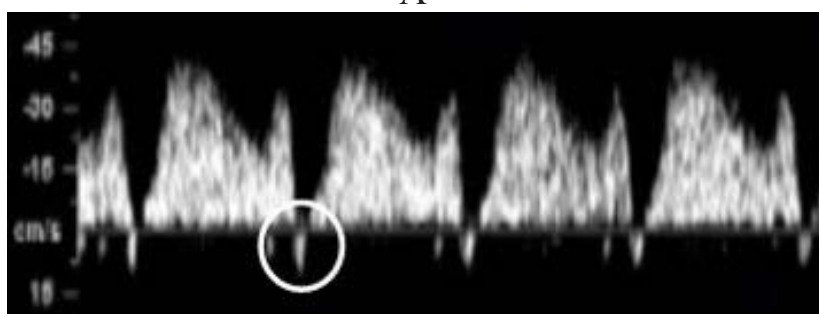

B

Figure 1 A: normal aspect of the ductus venosus flow; B: reversed flow of the ductus venosus 
Reduced or reversed flow during late diastole was interpreted as indicative of cardiac failure as it was assumed to reflect increased central venous pressure [19] (Figure $1 \mathrm{~A}$ and B). Flow reversal during atrial contraction indicates that the pressure in the right atrium in higher than in the portal system, but it does not mean necessarily heart failure. Restricted flow through the foramen oval, increased adrenergic drive could be seen in diastolic cardiac dysfunction and during hypoxia when the vessel wall compliance increases and the sphincter-like DV dilates [20]. Because the intrinsic renal function is not yet developed, the preload increases, as well as the circulating blood volume, affecting the fluid balance in the 11-14 weeks of gestation. As placental resistance is still high, the afterload also increases. The immature ventricles, who are less compliant, and the small alterations of the intravascular volume could be enough to produce the abnormal DV flow patterns $[19,21]$. The abnormal flow pattern could be caused by a temporary abnormality of the DV, possible abnormal diameter regulation or increased vessel compliance. An abnormal DV flow profile in fetuses with an increased NT measurement is associated with CHD, chromosomal malformation and an adverse pregnancy outcome $[22,23,24]$. As the increased NT disappears, the DV flow returns to normal $[25,26]$. The conclusion after observing the data from seven studies, including 600 chromosomally normal fetuses with a NT $>95$ th percentile, was that $4.8 \%$ of the fetuses had CHD and from those, $96.6 \%$ had an abnormal DV flow pattern at 11-13+6 weeks of gestation [27].

Direct measurement of cardiac function is required to determine if impaired cardiac function is responsible for increased NT measurement or not. Measuring the left ventricular ejection fraction on fetuses with a ventricular septal defect around 20 weeks of gestation, Simpson and Sharland [28] showed no difference between those who had an increased NT an those who not, but a normal cardiac function at this age of gestation does not exclude a cardiac dysfunction at the time when the NT was increased. It was demonstrated that there is no causal relationship between the increased NT and diastolic, systolic or global cardiac dysfunction by measuring the myocardial performance index and E/A ratio across the atrioventricular valves in normal fetuses, fetuses with chromosomal defects, fetuses with CHD and fetuses with an increased NT ( $>4 \mathrm{~mm})$ at 11-14 weeks of gestation [29].

\section{Tricuspid regurgitation [TR] at 11-14 weeks of gestation and congenital heart disease}

The etiology of the TR is still uncertain and may be related to the alterations in the hemodynamic balance of the $11-14$ weeks fetus. Atrioventricular valve regurgitation in present in $6.3 \%$ of $7-8$ weeks old normal fetuses, increases to $44 \%$ at 10 weeks, falls to $3.5-6 \%$ at 11 to $13+6$ weeks of gestation and disappears with the disappearance of the NT [30]. Increased afterload and preload causes right ventricular dilatation which is almost never seen in the absence of CHD. TR is associated with aneuploidy trisomy 21 in particular - and its prevalence increases with TN thickness and is higher in fetuses with CHD that those without [31].

Increased fetal pulmonary vascular resistance and systemic pressure in the right ventricle limits the effect of intracardiac shunt [32].

\section{Disorders of neurogenesis and congenital heart disease}

The venous hemodynamics could be affected, retrogradely, by a delay in the reconnection of the lymphatic sacs with the venous system, causing an abnormal DV waveform. With the development of the lymphatic sacs, they may be remodeled into lymph nodes and the excess of fluid could drain away, explaining the nature of the increased NT.

The link between increased NT, CHD and the DV flow abnormalities could be explained by the 
same embryonic origin - the neural crest - of the neck, head and adrenergic nerves of the DV [33] and by the fact that blood vessels and nerves share many developmental genes [34]. It has been shown that the neural crest ablation and the subsequent migration abnormalities lead to the development of CHD [35].

Growth factors required for the normal development of the cardiac chambers could be affected by the flow patterns [23]. CHD may be caused by the flow disturbance, and not by the failure of migration of the neural crest cell [20].

It was shown that an insult at $6-8$ weeks of gestation could lead to a fluid retention [20]. CHD could result from the increased NT and altered growth factor expression caused by the disturbance in vascular endothelial development at $7-10$ weeks of gestation.

A normal early ecochardiogram does not exclude a major CHD that could progress during pregnancy [36,37]. A NT measurement between 2.5 $-3.5 \mathrm{~mm}$ may be followed by an echocardiogram at $18-20$ weeks of gestation [38].

A complete fetal echocardiogram requires expertise, modern equipment and uses an abdominal approach to define the situs and cardiac connection, cardiac chambers and their symmetry and flow , the crossing and the flow of the great vessels and color flow mapping [39] (Figure 2 A, B, C). Earlier fetal echocardiography performed after NT measurement may discover a CHD and gives the parents the possibility to make a decision regarding the continuation or the interruption of the pregnancy [40].

\section{Conclusion}

An increased NT may identify fetuses eligible for specialized ecochardiography. If it is found a TR or an abnormal DV Doppler flow profile associated, an early exclusion is necessary, with an echochardiography at 15-16 weeks of gestation.

An echochardiography it is recommended to be made at $18-22$ weeks of gestation in fetuses with NT $>95$ th percentile but $<99$ th percentile, or if it is found in addition, a TR or an abnormal DV flow pattern, an earlier ecochardiogram is required.

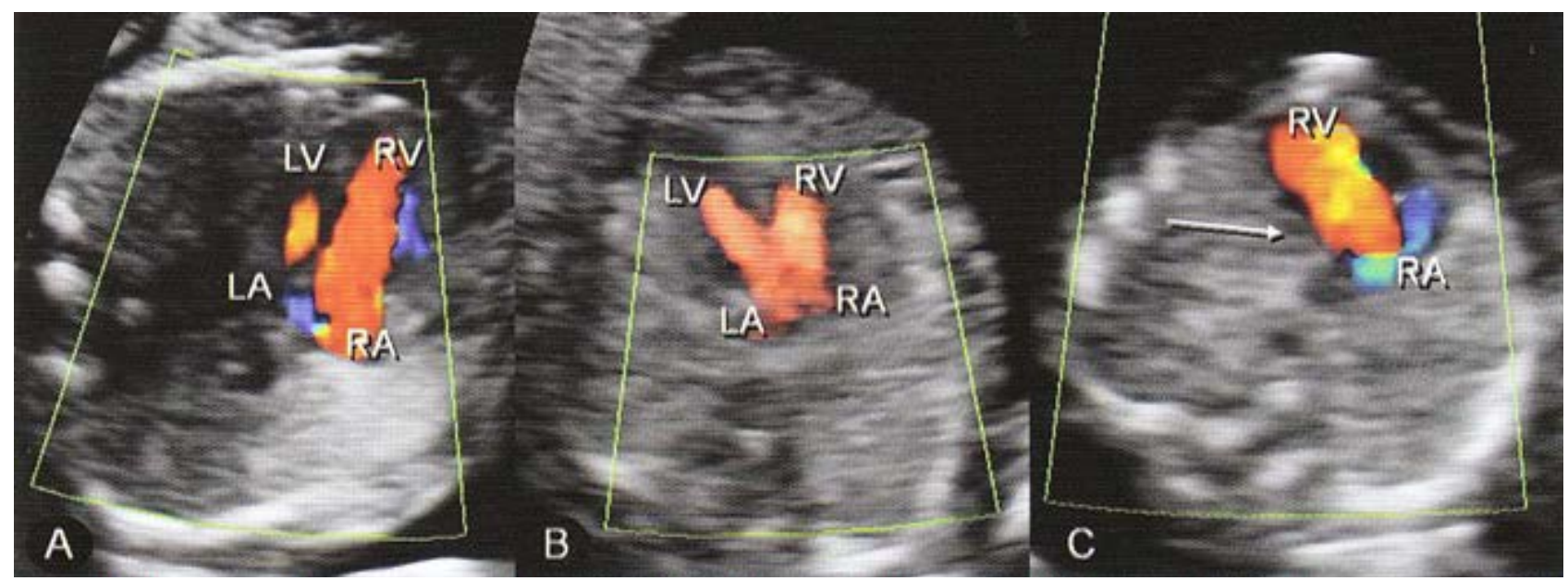

Figure 2: A: asymmetric left and right heart; B: Atrio-ventricular septal defect; $C$ : hypoplastic left heart 
9. Simpson L.L., Malone F.D., Saade G.R. \& D'Alton M.E. (2007). Nuchal translucency and the risk of congenital heart disease . Obstet Gynecol. 109, 1456 - 1457

1. Nicolaides K.H., Azar G., Byrne D., Mansur C. \& Marks K. (1992). Fetal nuchal translucency: ultrasound screening for chromosomal defects in first trimester of pregnancy. BMJ. 304, 867 - 869

2. Pajkrt E., Bilardo C.M., van Lith J.M.M., Mol B.W.J. \& Bleker O.P. (1995). Nuchal translucency measurement in normal fetuses. Obstet Gynecol. 86, $994-997$

3. Pandya P.P., Snijders R.J.M., De Johnson S.P., Luordes N.M. \& Nicolaides K.H. (1995). Screening for fetal trisomies by maternal age and fetal nuchal translucency thickness at 10-11 weeks of gestation. Br J Obstet Gynaecol. 102, $957-962$

4. Bilardo CM , Muller MA, Pajkrt E, Clur SA, van Zalen MM , Bijlsma EK . 2007 . Increased nuchal translucency and normal Karyotype : time for prenatal reassurance. Ultrasound Obstet Gynecol $30: 11-18$

5. Souka A.P., Von Kaisenberg C.S., Hyett J.A., Snoek J.D. \& Nicolaides K.H. (2005). Increased nuchal translucency with normal karyotype. $\mathrm{Am}$ J Obstet Gynecol. 192, 1005 - 1021

6. Westin M., Saaltvedt S., Bergman G., Almstrom H., Grunewald C. \& Valentin L. (2007) . By how much does increased nuchal transluncency increased the risk of adverse outcome in chromosomally normal fetuses? A study of 16Is measurement of nuchal translucency thickness a useful screening tool for heart defects? A study of 16260 fetuses derived from an unselected pregnant population. Ultrasound Obstet Gynecol. 29, $150-158$

7. Hyett J., Perdu M., Sharland G.K., Snijders R. \& Nicolaides K.H. (1999). Using fetal nuchal translucency to screen for major congenital cardiac defects at 10-14 weeks of gestation: population based cohort study. BMJ. $318,81-85$

8. Makrydimas G., Sotiriadis A. \& Ioannidis J.P. (2003). Screening performance of first - trimester nuchal translucency for major cardiac defects: a meta-analysis. Am J Obstet Gynecol. 189, 1330

10. Hyett J., Snoek J. \& Nicolaides K.H. (2007). Nuchal translucency and the risk of congenital heart disease. (Letter to editor). Obstet Gynecol. $109,1455-1456$

11. Ghi T., Huggon I.C., Zosmer N. \& Nicolaides K.H. (2001). Incidence of major structural cardiac defects associated with increased nuchal translucency but normal karyotype. Ultrasoung Obstet Gynecol. 18, 610 - 614

12. Makrydimas G., Sotiriadis A. \& Huggon I.C. et al. (2005). Nuchal translucency and fetal cardiac defects: a pooled analysis of major fetal echocardiography centers. Am J Obstet Gynecol. $192,89-95$

13. Hyett J. (2004). Does nuchal translucency have a role in fetal cardiac screening? Prenat Diagn. $24,1130-1135$

14. Galindo A., Comas C. \& Martinez J.M. et al. (2003). Cardiac defects in chromosomally normal fetuses with increased nuchal translucency at 10 - 14 weeks gestation. J Matern Fetal Neonatal Med. 13, $163-170$

15. Clur S.A., Mathijssen I.B. \& Pajkrt E. et al. (2008). Structural heart defects associated with an increased nuchal translucency: 9 years' experience in a referral center. Prenat Diagn. 28, $347-354$

16. Moll B.W.J. (1999). Down's syndrome, cardiac anomalies and nuchal translucency. Fetal heart failure might link nuchal translucency and Down's syndrome. BMJ. 318(7176), 70-71

17. Hyett J., Brizot M.L., von Kaisenberg C.S., McKie A.T., Farzaneh F. \& Nicolaides K.H. (1996). Cardiac gene expression of atrial natriuretic peptide and brain natriuretic peptide in trisomic fetuses. Obstet Gynecol. 87, $506-$ 510

18. Nicolaides K.H., Heath V. \& Cicero S. (2002). Increased fetal nuchal translucency at 11-14 weeks. Prenat Diagn. 22, 308 - 315

19. Matias A., Huggon I., Areias J.C., Montenegro N. \& Nicolaides K.H. (1999). Cardiac defects in 
chromosomally normal fetuses with abnormal ductus venosus blood flow at 10-14 weeks. Ultrasound Obstet Gynecol. 14, 307 - 310

20. Allan L.D. (2006). The mystery of nuchal translucency. The Mannheimer Lecture. Cardiol Young. 16, $11-17$

21. Leiva M.C., Tolosa J.E. \& Binotto C.N. et al. (1999). Fetal cardiac development and haemodynamics in the first trimester. Ultrasound Obstet Gynecol. 14, 167 - 174

22. Haak M.C., Twisk J.W., Bertelings M.M., Gittenberger de Groot A.C. \& van Vugt J.M. (2005). First trimester fetuses with increased nuchal translucency do not show altered intracardiac flow velocities. Ultrasound Obstet Gynecol. 25, 246 - 252

23. Sedmera D., Cook A.C., Shirali G. \& McQuinn T.C. (2005). Current issues and perspectives in hypoplasia of the left heart. Cardiol Young. 15, $56-72$

24. Oh C., Harmam C. \& Baschat A.A. (2007). Abnormal first trimester ductus venosus blood flow: a risk for adverse outcome in fetuses with normal nuchal translucency. Ultrasound Obstet Gynecol. 30, 192 - 196

25. Huisman T.W.A. \& Bilardo C. (1997). Transient increase in nuchal translucency thickness and reverse end - diastolic ductus venosus flow in a fetus with trisomy 18. Ultrasound Obstet Gynecol. 10, 397 - 399

26. Matias A., Gomes C., Flack N., Montenegro N. \& Nicolaides K.H. (1998). Screening for chromosomal abnormalities at $10-14$ weeks: the role of the ductus venous blood flow. Ultrasound Obstet Gynecol 12, 380 - 384

27. Maiz N., Plasencia W., Dagklis T., Faros E. \& Nicolaides K.H. (2008). Ductus venosus Doppler in fetuses with cardiac defects and high nuchal translucency thickness. Ultrasound Obstet Gynecol. 31, 256 - 260

28. Simpson J.M. \& Sharland G.K. (2000). Nuchal translucency and congenital heart defects: heart failure or not? Ultrasound Obstet Gynecol 16, $30-36$

29. Huggon I.C., Turan O. \& Allan L.D. (2004). Doppler assessment of cardiac function at 1114 weeks' gestation in fetuses with normal and increased nuchal translucency. Ultrasound Obstet Gynecol. 24, 390 - 398

30. Faiola S., Tsoi E., Huggon I.C., Allan L.D. \& Nicolaides K.H. (2005). Likelihood ratio for trisomy 21 in fetus with tricuspid regurgitation at 11 to $13+6$ weeks scan. Ultrasound Obstet Gynecol. 26, $22-27$

31. Huggon I.C., DeFigueiredo D.B. \& Allan L.D. (2003). Tricuspid regurgitation in the diagnosis of chromosomal anomalies in the fetus at $11-14$ weeks of gestation. Heart. 89, $1071-1073$

32. Rudolph A.M. (2001). Congenital Diseases of the Heart (2nd ed). (pp. 3-44). New York: Futura Publishing Company

33. Coceani F., Adeagbo A.S., Cutz E. \& Olley P.M. (1984). Autonomic mechanism in the ductus venosus of the lamb. Am J Physiol. 247, H17 $\mathrm{H} 24$

34. Carmeliet P. (2003). Blood vessels and nerves: common signals, pathways and diseases. Nat Rev Genet. 4, $710-720$

35. Kirby M.L. (1991). Neural crest and the morphogenesis of the Down syndrome with special emphasis on cardiovascular development. Prog Clin Biol Res. 373, 215 - 225

36. Yagel S., Cohen S.M. \& Messing B. (2007). First trimester fetal heartscreening. Curr Opin Gynecol. 19, 183 - 190

37. Carvalho J.S. (2004). Fetal heart scanning in the first trimester. Prenat Diagn. 24, 1060 - 1067

38. Lee W., Allan L. \& Carvalho J.S. et al. (2008). ISUOG consensus statement: what constitutes a fetal echocardiogram? Ultrasound Obstet Gynecol. 32, $239-242$

39. Johnson B. \& Simpson L.L. (2007). Screening for congenital heart disease: A move toward earlier echochardiography. Am J Perinatol. 24, $449-456$

40. Bronshtein M., Zimmer E.Z. \& Blazer S. (2008). The utility of detailed first trimester ultrasound examination in abnormal fetal nuchal translucency. Prenat Diagn. 28, 1037 - 1041 